\title{
The Effects of Anti-inflammatory Drug Treatment in Gastric Cancer Prevention: an Update of a Meta- analysis
}

Pengfei Kong1, ${ }^{*}$, Ruiyan $\mathrm{Wu}^{1^{*}}$, Xuechao Liu ${ }^{1,3^{*}}$, Jianjun Liu ${ }^{1,3^{*}}$, Shangxiang Chen ${ }^{1,3}$, Minting Ye ${ }^{1,2}$, Chenlu Yang1, 4, Ze Song1, 5, Wenzhuo He ${ }^{1,2}$, Chenxi Yin ${ }^{1,6}$, Qiong Yang1, 2, Chang Jiang, ${ }^{1,2}$, Fangxin Liao ${ }^{1,4}$, Roujun Peng ${ }^{1,2}$, Zhiwei Zhou ${ }^{1,3}$, Dazhi $\mathrm{Xu}^{1,3}$, Liangping $\mathrm{Xia}^{1,2}$

1. State Key Laboratory of Oncology in South China, Collaborative Innovation Centre for Cancer Medicine, Guangzhou, 510000, PR China;

2. Department of the VIP region, Sun Yat-sen University Cancer Centre, Guangzhou, 510000, PR China;

3. Department of Gastric and Pancreatic Surgery, Sun Yat-sen University Cancer Centre, Guangzhou, 510000, PR China;

4. Department of the Gynaecologic Oncology Surgery, Sun Yat-sen University Cancer Centre, Guangzhou, 510000, PR China;

5. Department of the Medical Imaging and Interventional Radiology, Sun Yat-sen University Cancer Centre, Guangzhou, 510000, PR China;

6. Department of the ICU, Sun Yat-sen University Cancer Centre, Guangzhou, 510000, PR China.

* Equal contributors.

$\square$ Corresponding author: Liangping Xia, MD, PhD, Department of the VIP region, Sun Yat-sen University Cancer Centre, Guangzhou, China, 651\# East Dongfeng Road, Guangzhou 510000, Guangdong Province, PR China. Fax: (+86) 020-87343107. E-mail: xialp@sysucc.org.cn.

( ) Ivyspring International Publisher. Reproduction is permitted for personal, noncommercial use, provided that the article is in whole, unmodified, and properly cited. See http://ivyspring.com/terms for terms and conditions.

Received: 2016.06.18; Accepted: 2016.09.18; Published: 2016.11.09

\begin{abstract}
Gastric cancer has high incidence and fatality rates, making chemoprevention agents necessary. There is an ongoing debate about aspirin/nonsteroidal anti-inflammatory drugs (NSAIDs) use can significant reduce the risk of GC. We conducted a meta-analysis of existing studies evaluating the association of anti-inflammatory drug and GC. We performed a systematic literature search of PubMed, Web of Science, Embase, OVID, Cochrane Library and Clincialtrials.gov up to August 31, 2015. Either a fixed-effects or a random-effects model using was based on the result of homogeneity analysis. Subgroup, sensitivity, meta-regression, and publication bias analyses were evaluated. Forty-seven studies were finally included in this meta-analysis. The overall GC risk reduction benefit associated with anti-inflammatory drug use represented an $R R$ of $0.78(95 \% \mathrm{Cl}$ 0.71 to 0.85 ) and an adjusted RR of $0.74(95 \% \mathrm{Cl} 0.71$ to 0.77$)$. Besides, the prevention benefit of aspirin/NSAIDs ingestion appeared to be confined to those patients with regiment of short or middle-term ( $\leq 5$ years), high-frequency ( $>30$ times per month) and low dose $(<200 \mathrm{mg}$ per day). Further, our data also suggest that COX-2 inhibitors use is a more effective approach in GC prevention (RR, $0.45 ; 95 \% \mathrm{Cl}, 0.29-0.70)$. In this meta-analysis, our finding support short or middle-term ( $\leq 5$ years), high-frequency ( $>30$ times per month) and low dose ( $<200 \mathrm{mg}$ per day) aspirin/NSAIDs intake is a well method for GC prevention and also confirm the inverse association between aspirin/NSAIDs use and GC risk. Additionally, selective COX-2 inhibitors use probably a more effective approach to reduce GC risk.
\end{abstract}

Key words: anti-inflammatory drug, gastric cancer, risk factor, prevention, meta-analysis.

\section{Introduction}

Globally, there were 951,600 new gastric cancer (GC) cases and accounted for 723,100 deaths in 2012[1]. GC is a major public health burden internationally, especially in parts of the developing countries $(677,100$ new cases in 2012). Recently, some therapeutic advances its prognosis is often unfavourable, and despite the decrease in overall incidence[2]. Thus, effective and inexpensive strategies for prevention of 
GC are urgently needed in the developing world.

Non-steroidal anti-inflammatory drug (NSAID) are a structurally diverse group of drugs that are most widely used to treat pain, inflammation and fever over the past decades, fundamentally including aspirin, celecoxib, acetaminophen, and other NSAIDs. These drugs are inhibitors of the enzyme cyclooxygenase (COX) and thereby affect the production of prostaglandin signalling molecules (PGs). Two isoforms of COX are well-known: COX-1 for the production of PGs during basal conditions in the gastrointestinal tract and an inducible COX-2 regulated by growth factors, mitogens, and tumor promoters [3]. Until recently, compelling data from a large and rapidly expanding body of studies indicate that aspirin and other NSAIDs is associated with a decreased risk of colorectal, lung, and other carcinomas [4-6]. Nevertheless, the exact mechanism of risk reduction is still undetermined but may be related to these agents have decreased the level of prostaglandin E2 (PGE2). It is reported that PGE2 may modulate various immune responses, increase cells' longevity via inhibition of apoptosis, and stimulate cancer cell proliferation [7-9]. Since 1970s, a host of prior large epidemiologic studies and meta-analyses strongly support a protective association between aspirin/NSAIDs ingestion and gastric adenocarcinomas [10-18]. However, several studies argue that using aspirin or other NSAIDs does not lower risk of GC [19-21]. More recently, many novel studies have payed close attention to this topic [22-29]. Therefore, it is necessary to conduct an update metaanalysis for aspirin/NSAIDs use and GC. In addition, it is still unclear that the optimal regiment for GC prevention.

In the present study, we performed an update systematic review of existing studies to explore the association between aspirin/NSAID intake and GC risk and a better benefit regiment for GC risk reduction.

\section{Materials and Methods}

\section{Search strategy}

We aimed to conduct a systematic review (according to PRISMA statement) identify association between anti-inflammatory drug exposure and risk of gastric cancer. A literature search was performed in the databases of Medline (PubMed), Web of Science, Embase, OVID, Cochrane Library and Clincialtrials.gov before August 31, 2015 for related publications, using the following key words: ("aspirin" or "NSAIDs" or "non-steroidal" or "antiinflammatory" or "cyclooxygenase inhibitors" or " COX") combined with ("gastric cancer" or "stomach cancer" or "gastric adenocarcinoma" or "stomach adenocarcinoma" ) (for detail search terms see Supplementary Table S1). The retrieved articles were strictly examined to exclude duplicates or overlapping studies. In addition, reference lists of all retrieved articles and previous Meta-analyses were also checked for further eligible publications.

\section{Selection criteria}

Eligibility of articles were assessed independently by two reviewers (P. F. Kong and J. J. Liu). Our inclusion criteria for article were as follows: (1) exposure to any type of anti-inflammatory drugs; (2) measured the occurrence of gastric cancer; (3) randomized clinical trials (RCTs), cohort studies, or case-control studies; and (4) the odds ratios (OR) or relative risks (RR) and corresponding $95 \%$ confidence intervals (CIs) were provided directly or calculated indirectly. In addition, reference lists of all retrieved articles and previous systematic reviews were checked for further qualified publications. For the multiple articles from the same population or data sets, only the most detailed or recent information were extracted. If necessary, authors were contacted for the detail or additional unpublished data. Animal studies, review articles, case reports, editorials, commentaries, and duplicate studies were excluded. The entire process of study selection is summarized in Figure 1.

\section{Data extraction and assessment}

Two reviewers (P. F. Kong and R. Y. Wu) extracted the data independently and any disagreement was resolved by discussion. Briefly, the following information and potential confounders were extracted: first author, publication year, country, study design, population characteristics (i.e., number, age, and follow-up duration), medication type, frequency of use, information source for exposure measurement, and total number of persons or person years in each comparison group. Additionally, we evaluated the quality of the included studies using the NewcastleOttawa scale [30].

\section{Statistical analysis}

Our meta-analysis was conducted to assess the efficacy of pre-diagnosis aspirin usage on incidence of GC. For observational study, we used the PRISMA guidelines for meta-analysis on data extraction, analysis, and reporting. Heterogeneity between individual studies was quantified by $\chi^{2}$ test and $I^{2}$ test, respectively. $\quad \mathrm{p}<0.05$ and/or $I^{2}>50 \%$ suggests significant heterogeneity [30]. Summary RRs (HRs) and $95 \% \mathrm{CI}$ were calculated using a random-effects model for $I^{2}>50 \%$, and a fixed-effects model was applied when the heterogeneity was not significant. The Galbraith plots was used to visualize the impact 
of individual studies on the overall homogeneity test statistic [31]. Subgroup analyses were further conducted according to study designs (case-control, cohort or RCT), sample sources (population-based or hospital-based), geographical region (North America, Europe, and Asia), sites of cancer (cardia or noncardia), exposure type (aspirin, celecoxib, acetaminophen, COX-2 inhibitors, and other NSAIDs), use at reference date (former and current), study quality (high and low), publication year $(\leq 2000$ and $>2000)$, sample size $(\leq 1000$ and $>1000)$, frequency, duration, dose effects $(<200 \mathrm{mg}, 200$ to $750 \mathrm{mg}$, $>750 \mathrm{mg}$ ), and adjustments for covariates, so as to investigate the deprive of heterogeneity. Sensitivity and subgroup analyses were used to dissect the heterogeneity. As described previously, to evaluate the publication bias risk, funnel plots were evaluated. Two-sided $\mathrm{p}$ values were calculated, with a $\mathrm{p}$ value $<0.05$ considered significant for all tests. All analyses were performed using the Stata software (V.19.0; Stata Corp, College Station, Texas, USA) [32].

\section{Results}

\section{Search results, study characteristics and quality Assessment}

Our search strategy identified 18530 articles for eligibility, of which 257 were potentially relevant upon initial inspection of study topics. Forty-seven studies, comprising 2,345,540 patients and over 13,500 events reported the association between anti-inflammatory drug use and the risk of GC, met all of the selection criteria and were included in our meta-analysis (Figure 1) [10-15, 19, 21-29, 33-63]. Of these enrolled articles, nine were RCT studies $[12,23,27,29,38,44$, $48,52,61]$, fifteen were cohort studies $[15,24,26,28$, $33-37,45,46,58-60,62]$, and the remaining twentythree were case-control studies $[10,11,13,14,21,22$, $24,25,39-43,47,49-51,53,54,56,57,63]$. In our study, there were conducted, respectively, seventeen in North America [13-15, 21, 28, 35-37, 39, 43, 44, 47, 48, 53, 54, 57, 58], seventeen in Europe [11, 12, 27, 33, 34, $38,40-42,45,46,49,50,59,60,62,63]$, eleven in Asia $[22-26,29,51,52,61]$, and two in Australia [10, 56].

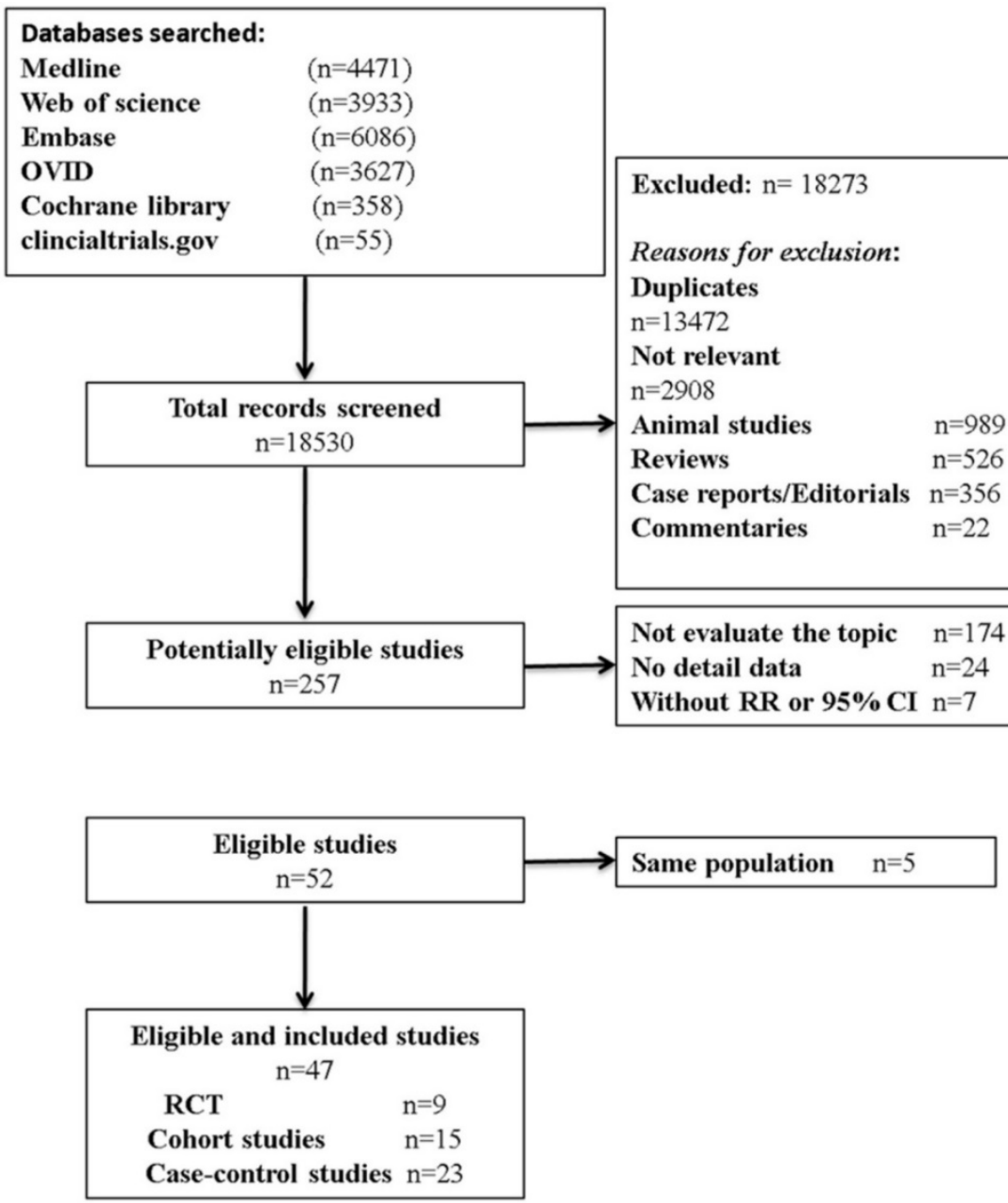

Figure 1. Flow diagram of study identification, screening, eligibility and inclusion. 
Additionally, the detail characteristics of the included studies are presented in Table 1 and Supplementary Table S2.

As shown in Supplementary Table S3 and Supplementary Table S4, the methodological quality scores of 38 included observational studies ranged from 6 to 9 , with an average of 7.95. The average scores were 7.96 for case-control studies and 7.93 for cohort studies, respectively. In addition, RCTs quality scores were also evaluated in Supplementary Table S5. Altogether, we demonstrated mostly enrolled studies with a high quality in our study.

\section{Anti-inflammatory drug intake and gastric cancer risk}

A pooled analysis was conducted on all 47 studies. The multivariable-adjusted RRs for each study and the combined RR for anti-inflammatory drug intake and the risk of GC are presented in Figure 2. Among all studies, 42 showed an inverse association between the anti-inflammatory drug and GC risk, 14 of which were statistically significant. Overall, the pooled analysis represented a summary RR of 0.78 (95\% CI 0.71 to 0.85$)$ with significant heterogeneity $\left(I^{2}=78.7 \%, \mathrm{p}<0.0001\right)$.

Table 1. Characteristics of included studies.

\begin{tabular}{|c|c|c|c|c|}
\hline Author/Year & Study design & Country & Number of events & Total subjects \\
\hline Gillies[10]/1968 & $\mathrm{HCC}$ & Australia & 6 & 50 \\
\hline Isomaki[33]/1978 & Cohort & Finland & 285 & 46101 \\
\hline Gridley[34]/1993 & Cohort & Sweden & 101 & 11683 \\
\hline Thun[35]/1993 & Cohort & America & 308 & 1080089 \\
\hline Schreinemachers[36]/1994 & Cohort & America & 39 & 12668 \\
\hline Cibere[37]/1997 & Cohort & Canada & 10 & 862 \\
\hline ТРТ[38]/1998 & $\mathrm{RCT}$ & United Kingdom & 1 & 5094 \\
\hline Farrow[14]/1998 & PCC & America & 612 & 1299 \\
\hline Amjad[39]/1998 & $\mathrm{HCC}$ & America & 16 & 40 \\
\hline Zaridze[40]/1999 & $\mathrm{HCC}$ & Russia & 448 & 1058 \\
\hline Suleiman[41]/2000 & PCC & United Kingdom & 56 & 112 \\
\hline Langman[42]/2000 & PCC & United Kingdom & 188 & 2018 \\
\hline Coogan[43]/2000 & $\mathrm{HCC}$ & America & 250 & 6083 \\
\hline Akre[11]/2001 & PCC & Sweden & 397 & 1327 \\
\hline Fischbach[44]/2001 & $\mathrm{RCT}$ & America & 1 & 284 \\
\hline Sorensen[45]/2003 & Cohort & Denmark & $276.56^{*}$ & 344114 \\
\hline S Friis[46]/2003 & Cohort & Denmark & 68 & 29470 \\
\hline Nomura[47]/2003 & PCC & America & 299 & 745 \\
\hline Ratnasinghe[15]/2004 & Cohort & America & 48 & 22834 \\
\hline Gammon[21]/2004 & PCC & America & 350 & 1042 \\
\hline Cook NR[48]/2005 & $\mathrm{RCT}$ & America & 20 & 39876 \\
\hline Lindblad[49]/2005 & PCC & United Kingdom & 2348 & 22348 \\
\hline Martin W[50]/2005 & $\mathrm{HCC}$ & United Kingdom & 25 & 616 \\
\hline HB Yang[51]/2006 & $\mathrm{HCC}$ & China & 113 & 250 \\
\hline Wai K[52]/2006 & $\mathrm{RCT}$ & China & 24 & 213 \\
\hline Fortuny[53]/2007 & PCC & America & 1488 & 8916 \\
\hline Flossmann[12]/2007 & $\mathrm{RCT}$ & United Kingdom & 112 & 13664 \\
\hline Duan L[54]/2008 & PCC & America & 714 & 2074 \\
\hline Sadeghi[56]/2008 & PCC & Australia & 425 & 2006 \\
\hline Figueroa[57]/2009 & PCC & America & 367 & 1062 \\
\hline Cathrine[13]/2009 & PCC & America & 109 & 316 \\
\hline Abnet CC[28]/2009 & Cohort & America & 360 & 311115 \\
\hline Epplein M[58]/2009 & Cohort & America & 643 & 169292 \\
\hline $\mathrm{Wu}[26] / 2009$ & Cohort & China & 172 & 52161 \\
\hline Manas[59]/2009 & Cohort & Spain & 23 & 302 \\
\hline Steevens[60]/2010 & Cohort & Netherland & 655 & 120852 \\
\hline Yanaoka[61]/2010 & RCT & Japan & 6 & 47 \\
\hline Gonzalez[62]/2010 & Cohort & Spain & 21 & 478 \\
\hline Bertuccio[63]/2010 & $\mathrm{HCC}$ & Italy & 229 & 872 \\
\hline Rothwell[27]/2011 & $\mathrm{RCT}$ & United Kingdom & 71 & 25570 \\
\hline Lee J[25]/2012 & $\mathrm{HCC}$ & Korea & 983 & 1966 \\
\hline Wong[29]/2012 & $\mathrm{RCT}$ & China & 9 & 1024 \\
\hline Sheu[23]/2012 & $\mathrm{RCT}$ & China & 3 & 140 \\
\hline Yanmin $\mathrm{Wu}[22] / 2013$ & $\mathrm{HCC}$ & China & 501 & 1024 \\
\hline Gong[24]/2014 & $\mathrm{HCC}$ & Korea & 327 & 654 \\
\hline Ajdarkosh[22]/2015 & $\mathrm{HCC}$ & Iran & 7 & 688 \\
\hline Sungmo Jung[24]/2015 & Cohort & Korea & 19 & 1041 \\
\hline
\end{tabular}


In addition, the RRs were 0.84 (95\% CI 0.65 to 1.10) for RCT studies, 0.81 (95\% CI 0.67-0.98) for cohort studies, and 0.84 (95\% CI 0.70 to 1.00) for case-control studies, respectively. In the six studies focus on GCspecific risk, there were in a relative low quality when using the Newcastle-Ottawa scale system to evaluate. $[25,29,48,51,59,61]$ After excluding the study with relative low quality, the heterogeneity extremely decreased across all studies $\left(I^{2}=39.0 \%, \mathrm{p}=0.007\right)$ and the adjusted RRs were 0.74 (95\% CI 0.71 to 0.77 ) (Figure 2). Accordingly, anti-inflammatory drug intake can significantly reduce the risk of GC.

\section{Frequency and duration of anti-inflammatory drug use}

As shown in Table 2, the frequency of aspirin, COX-2 inhibitors and other NSAIDs use was divided into 4,2 , and 3 subgroups, respectively. We found an apparent trend with increasing frequency of drug use and GC risk reduction. On the one hand, in aspirin group, $\mathrm{RR}=0.9195 \% \mathrm{CI} 0.77-1.08$, for 1 to 15 times/month users; RR $=0.79,95 \%$ CI $0.64-0.98$, for 16 to 29 times/month users; $\mathrm{RR}=0.74,95 \%$ CI 0.59-0.92, for $>30$ times/month users. On the other hand, in other NSAIDs group, RR=0.9795\% CI 0.77-1.21, for 1 to 15 times/month users; RR $=0.98,95 \%$ CI 0.79-1.23, for 16 to 29 times/month users; $\mathrm{RR}=0.72,95 \%$ CI $0.59-0.88$, for $>30$ times/month users. In addition, we also divided the duration time of different antiinflammatory drugs into 4 (aspirin subgroup: $\leq 1$ years, 2 to 5 years, 6 to 9 years, and $>10$ years), 2 (COX-2 subgroup: $\leq 1$ years and 2 to 5 years), and 3 (other NSAIDs subgroup: $\leq 1$ years, 2 to 5 years, and 6 to 9 years), respectively. Notably, we observed an unexpected trend of decreasing risk of GC associated with decreasing duration of anti-inflammatory drugs use. For instance, in aspirin group, $\mathrm{RR}=0.6995 \% \mathrm{CI}$ $0.48-0.99$, for $\leq 1$ years users; $R R=0.74,95 \%$ CI $0.63-$ 0.87 , for 2 to 5 years' users; $R R=0.81,95 \%$ CI $0.59-1.13$, for 6 to 9 years' users; RR $=0.86,95 \%$ CI $0.48-1.55$, for $>10$ years users. Furthermore, in COX-2 inhibitors users, compare with daily intake subgroup $(R R=0.48$, 95\% CI 0.30-0.78), the summary RR for twice daily intake subgroup ( $R R=0.30,95 \%$ CI $0.09-1.07$ ) was lower. In our study, a linear positive correlation trend was found between duration of aspirin use and GC risk, though the result was not statistically significant ( $\mathrm{P}$ for linear trend $=0.210$; Supplementary Figure S1). As a consequence, we unravel a tendency towards stronger risk reduction for more frequent and short term aspirin usage.
A

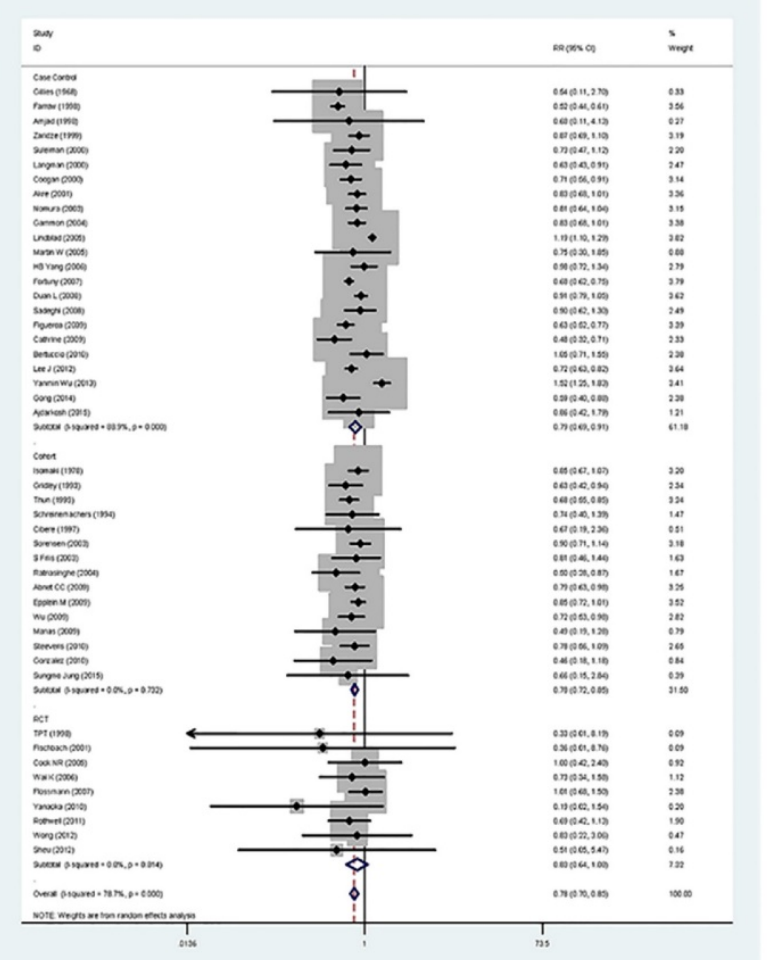

B

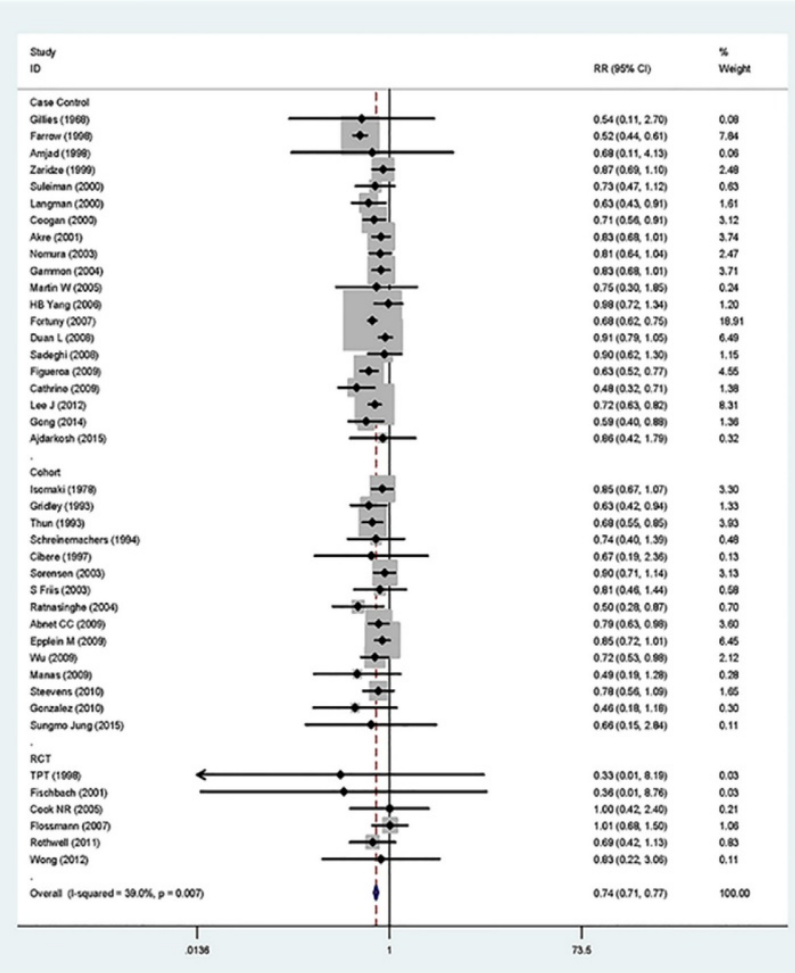

Figure 2. Forest plot of anti-inflammatory drug intake and risk of gastric cancer (ever use vs, nonuse). (A) Overall and (B) adjust for study quality. The pooled relative risk was achieved using random-effects model $(12>50 \%)$ and fix-effects model $(12 \leq 50 \%)$. Grey square represents relative risk in each study, with square size reflecting the study-specific weight and the $95 \% \mathrm{Cl}$ represented by horizontal bars. Squares or diamonds to the left of the solid vertical line indicate benefit with anti-inflammatory drug intake. 
Table 2. Frequency and duration on anti-inflammatory drug intake and gastric cancer risk.

\begin{tabular}{|c|c|c|c|c|c|c|c|c|}
\hline \multirow[t]{2}{*}{ Exposure type } & \multicolumn{4}{|l|}{ Frequency of use } & \multicolumn{4}{|c|}{ Duration of time } \\
\hline & Frequency (times/month) & NO. of reports & RR $(95 \%)$ & $\mathrm{P}$ & Time (years) & NO. of reports & RR (95\%) & $\mathrm{P}$ \\
\hline \multirow[t]{4}{*}{ Aspirin } & Occasionally & 4 & $0.96(0.80,1.17)$ & 0.714 & $\leq 1$ & 3 & $0.69(0.48,0.99)$ & 0.047 \\
\hline & $1-15$ & 6 & $0.91(0.77,1.08)$ & 0.273 & $2-5$ & 7 & $0.74(0.63,0.87)$ & 0.028 \\
\hline & $16-29$ & 6 & $0.79(0.64,0.98)$ & 0.031 & $6-9$ & 9 & $0.81(0.59 .1 .13)$ & 0.211 \\
\hline & $30+$ & 8 & $0.74(0.59,0.92)$ & 0.007 & $10+$ & 2 & $0.86(0.48,1.55)$ & 0.621 \\
\hline \multirow[t]{2}{*}{ COX-2 inhibitors } & 30 (Daily) & 4 & $0.46(0.29,0.72)$ & 0.001 & $\leq 1$ & 3 & $0.48(0.30,0.78)$ & 0.003 \\
\hline & 60 (Twice daily) & 1 & $0.42(0.08,2.13)$ & 0.293 & $2-5$ & 2 & $0.30(0.09,1.07)$ & 0.064 \\
\hline \multirow[t]{3}{*}{ Other NSAIDs } & $1-15$ & 7 & $0.97(0.77,1.21)$ & 0.759 & $\leq 1$ & 6 & $0.76(0.66,0.88)$ & $<0.0001$ \\
\hline & $16-29$ & 5 & $0.98(0.79,1.23)$ & 0.880 & $2-5$ & 9 & $0.77(0.70,0.84)$ & $<0.0001$ \\
\hline & $30+$ & 7 & $0.72(0.59,0.88)$ & 0.002 & $6-9$ & 6 & $0.75(0.65,0.87)$ & $<0.0001$ \\
\hline
\end{tabular}

Abbreviations: RR, relative risk, COX-2: cyclooxygenase-2, NSAIDs: nonsteroidal anti-inflammatory drugs.

\begin{tabular}{|c|c|c|}
\hline Study & & $\%$ \\
\hline ID & $\operatorname{RR}(95 \% \mathrm{Cl})$ & Weight \\
\hline$<200 \mathrm{mg}$ & & \\
\hline TPT (1998) & $0.33(0.01,8.19)$ & 0.44 \\
\hline S Friis (2003) & $1.01(0.59,1.72)$ & 7.94 \\
\hline Cook NR (2005) & $1.00(0.42,2.40)$ & 2.95 \\
\hline Rothwell (2011) & $0.69(0.42,1.13)$ & 11.45 \\
\hline Fortuny (2007) & $0.46(0.32,0.68)$ & 28.70 \\
\hline $\begin{array}{l}\text { Subtotal }(\mathrm{I}-\text { squared }=42.1 \%, \mathrm{p}=0.141) \\
(200,750) \mathrm{mg}\end{array}$ & $0.63(0.49,0.80)$ & 51.49 \\
\hline Flossmann (2007) & $1.01(0.68,1.50)$ & 14.59 \\
\hline Fortuny (2007) & $0.61(0.43,0.87)$ & 25.57 \\
\hline $\begin{array}{l}\text { Subtotal ( }(\text {-squared }=71.8 \%, p=0.059 \text { ) } \\
>750 \mathrm{mg}\end{array}$ & $0.76(0.59,0.98)$ & 40.16 \\
\hline Fortuny (2007) & $0.94(0.58,1.54)$ & 8.35 \\
\hline Subtotal $(I-$ squared $=. \%, p=)$. & $0.94(0.58,1.54)$ & 8.35 \\
\hline Overall (I-squared $=44.4 \%, p=0.083$ ) & $0.71(0.60,0.84)$ & 100.00 \\
\hline $\begin{array}{c}1 \\
.0136\end{array}$ & & \\
\hline
\end{tabular}

Figure 3. Forest plot of different dose aspirin intake and risk of gastric cancer. The pooled relative risk was achieved using fix-effects model. Grey square represents relative risk in each study, with square size reflecting the study-specific weight and the $95 \% \mathrm{Cl}$ represented by horizontal bars. Squares or diamonds to the left of the solid vertical line indicate benefit with aspirin intake.

\section{Dose-response effect}

Twelve studies that reported the RR and its $95 \%$ CI for the exact dose were included in our doseresponse meta-analysis, six for aspirin $[19,21,38,52$, 53, 62], five for COX-2 inhibitors [25, 27, 50, 51, 59], and one for other NSAIDs [28]. The summary RR for $<200$ $\mathrm{mg}$ /day of aspirin was 0.63 (95\% CI, 0.49-0.81) with a heterogeneity $\left(\mathrm{P}=0.141, I^{2}=42.1 \%\right)$. However, for users of more than $200 \mathrm{mg} /$ day, there were no monotonically decreasing trend, and on the contrary, a monotonically increasing trend was observed (RR $=0.76,95 \%$ CI $0.59-0.98$, for 200 to $750 \mathrm{mg} /$ day; $\mathrm{RR}=$ $0.94,95 \%$ CI $0.58-1.54$, for $>750 \mathrm{mg} /$ day). Additionally, the summary RR for $200 \mathrm{mg} /$ day of COX-2 inhibitors was 0.50 (95\% CI, 0.30-0.84) without heterogeneity (P $=0.989, \quad I 2=0.0 \%)$. The rest results present in Supplementary Table S6 and Figure 3.

\section{Subgroup analysis}

\section{1). Study design}

Subgroup analysis by study design was conducted. Significant inverse associations were observed in cohort studies (RR, $0.81 ; 95 \% \mathrm{CI}, 0.67-0.98)$ and case-control studies (RR, 0.84; 95\% CI, 0.70-1.00). In addition, pooled analysis of RCTs showed a borderline significant decrease in GC to be associated with anti-inflammatory drug intake (RR, 0.84 95\% CI, 0.65-1.10). (Table 3). 


\section{2). Geographic area}

Studies were stratified by geographic area, The RRs were $0.71 \quad(95 \% \mathrm{CI}, 0.64-0.79)$ for studies conducted in North America, 0.83 (95\% CI, 0.72-0.96) for studies in Europe. These results indicate a significant inverse association between antiinflammatory intake and GC risk (Supplementary Table S7).

\section{3). Site of cancer}

The possible association between the use of NSAIDs and site of GC was reported by twenty-three studies, thirteen in cardia [11-15, 26, 40, 41, 52, 54-57], and ten in non-cardia [11-15, 40,52,55-57]. In this subgroup analysis, cardia and non-cardia group both were existed heterogeneity, and all of the pooled analyses yielded statistically significant RRs. The protective effect of NSAIDs for non-cardia GC, with a pooled RR of 0.63 (95\% CI: 0.54-0.73), was greater than that for cardia GC, with a summary RR of 0.80 (95\% CI: 0.73-0.87) (Supplementary Table S7).

\section{4). Anti-inflammatory drug type}

Among subgroup analyses stratified by antiinflammatory drug types, studies on aspirin (RR, 0.80 ; 95\% CI, 0.73-0.87) [10-15, 19, 21, 23, 24, 35, 36, 38, 40, 47$49,52-57,61-63]$, studies on celecoxib (RR, 0.49 ; 95\% CI, $0.30-0.81)[25,27,50]$, studies on acetaminophen (RR, 0.95; 95\% CI, 0.83-1.10)[13, 54], studies on COX-2 inhibitors (RR, 0.45; 95\% CI, 0.29-0.70)[25, 27, 50, 51, 59], and studies on other NSAIDs (RR, $0.81 ; 95 \% \mathrm{CI}$, $0.75-0.89)[12-15,22,26,28,29,33,34,37,39-46,48,49$, $52,54-58,60]$. Except the acetaminophen group, all of other groups showed statistically significant RRs, the outcomes indicated anti-inflammatory drug intake can reduce the risk of GC (Table 3).

\section{Sensitivity analyses and evaluation of heterogeneity}

Sensitivity analyses were performed to explore possible causes of heterogeneity and the effect of various exclusion criteria on the overall result were examined. Twenty-two studies that were not adjusted for smoking, alcohol consumption, and BMI (body mass index) were omitted [10, 11, 19, 22, 28, 33, 34, 37, $39,41,44-46,49,52,53,56,58-60,62,63]$. The remaining studies produced an RR of 0.74 (95\% CI, 0.70-0.79), with substantial evidence of decreasing heterogeneity $\left(\mathrm{P}=0.043, I^{2}=37 \%\right)$. Restricting analysis to the eight studies that were adjusted for race produced similar results (RR: 0.74, 95\% CI: 0.66-0.84) [12, 13, 35, 38, 39, $43,52,55]$, but heterogeneity was still detectable $\left(\mathrm{P}=0.014, I^{2}=60.1 \%\right)$. Further exclusion of any single study did not change the overall outcomes, which ranged from 0.78 (95\% CI: $0.71-0.86)$ to 0.79 (95\% CI: 0.72-0.87).

Meta-regression analysis demonstrated that geographic area $(\mathrm{P}=0.10)$, study quality $(\mathrm{P}<0.001)$, and publication year of study $(\mathrm{P}=0.09)$ were significant sources of heterogeneity, but the outcomes indicate that study design, drug type, and study size were not the main origin of heterogeneity. Geographic area alone explained $10.12 \%$ of the $\tau^{2}$ in the metaregression analyses, study quality explained $61.75 \%$ of the $\tau^{2}$ and publication year explained $5.44 \%$ (Supplementary Table S8).

\section{Publication bias}

The funnel plot did not show any notable asymmetry (Supplementary Figure S2). No publication bias was detected using the Begg's test (P $=0.551)$ and Egger's test $(\mathrm{P}=0.070)$.

Table 3. Subgroup analyses of anti-inflammatory drug intake and gastric cancer risk.

\begin{tabular}{|c|c|c|c|c|c|}
\hline \multirow[b]{2}{*}{ Group } & \multirow[b]{2}{*}{$\begin{array}{l}\text { NO. of } \\
\text { reports }\end{array}$} & \multirow[b]{2}{*}{ RR (95\%) } & \multicolumn{2}{|c|}{ Heterogeneity test } & \multirow[b]{2}{*}{$I^{2}(\%)$} \\
\hline & & & $\chi^{2}$ & $\mathrm{P}$ & \\
\hline Total & 47 & $0.78(0.71,0.85)$ & 216.43 & $<0.0001$ & 78.70 \\
\hline \multicolumn{6}{|l|}{ Design } \\
\hline $\mathrm{RCT}$ & 9 & $0.84(0.65,1.10)$ & 4.46 & 0.814 & 0.00 \\
\hline Cohort & 15 & $0.81(0.67,0.98)$ & 10.41 & 0.732 & 0.00 \\
\hline Case-control & 23 & $0.84(0.70,1.00)$ & 198.25 & $<0.0001$ & 88.90 \\
\hline PCC & 12 & $0.81(0.64,1.12)$ & 277.73 & $<0.0001$ & 96.00 \\
\hline $\mathrm{HCC}$ & 11 & $0.88(0.69,0.85)$ & 51.00 & $<0.0001$ & 80.40 \\
\hline \multicolumn{6}{|l|}{ Exposure type } \\
\hline Aspirin & 26 & $0.80(0.73,0.87)$ & 61.83 & $<0.0001$ & 59.60 \\
\hline Celecoxib & 3 & $0.49(0.30,0.81)$ & 0.04 & 0.979 & 0.00 \\
\hline Acetaminophen & 2 & $0.95(0.83,1.10)$ & 0.13 & 0.715 & 0.00 \\
\hline COX-2 inhibitors & 5 & $0.45(0.29,0.70)$ & 0.81 & 0.937 & 0.00 \\
\hline Other NSAIDs & 28 & $0.81(0.75,0.89)$ & 65.60 & $<0.0001$ & 58.80 \\
\hline \multicolumn{6}{|c|}{ Use at reference date } \\
\hline Former & 5 & $0.88(0.70,1.11)$ & 8.86 & 0.065 & 54.80 \\
\hline Current & 5 & $0.69(0.49,0.99)$ & 29.02 & $<0.0001$ & 86.20 \\
\hline
\end{tabular}




\section{Discussion}

In this meta-analysis, data were available for more than 2.3 million individuals and more than 13,000 GC events. Our study has found several unexpected findings with important clinical implications.

First, this work provides first convincing evidence that probably short or middle-term ( $\leq 5$ years), high-frequency ( $>30$ times per month) and low dose ( $<200 \mathrm{mg}$ per day) anti-inflammatory drug use is associated with a statistically significant reduction in the risk of GC. For most of the 20th century, antiinflammatory drug commonly is a mainstay of the treatment of inflammatory and of acute pain such as stomach pain [64]. Currently, many studies identified that aspirin and other NSAIDs have played important roles in cancer prevention [65-67]. However, until recently, there has been no reliable data to unravel the exact dose and treatment regimen for optimal benefit for cancer prevention, especially in GC. In the present study, we unequivocally showed that short or middleterm ( $\leq 5$ years), high-frequency ( $>30$ times per month) and low dose ( $<200 \mathrm{mg}$ per day) anti-inflammatory drug intake could be a better regimen, which was related to significantly decreased risk of GC. Commonly, it is difficult to evaluate with precision the consumption of NSAIDs. One clinical trial has shown that a daily intake of aspirin about 6.8 years $(75 \mathrm{mg})$ present some obvious reductions in the incidence of GC [38]. Another study indicates that less than one year and one or more tablets per day were also effective [57]. There was, however, one study argues that daily intake of aspirin about 5 years $(500 \mathrm{mg})$ that did not offer any protection [53]. In one previous metaanalysis, Ye et al concluded that long-term ( $>4$ years) and low-frequency (1 to 4.5 times per week) aspirin use is associated with a significant reduction in the incidence of GC [18]. Surprisingly, in our study, we observed an unexpected trend of decreasing risk of GC associated with decreasing duration of antiinflammatory drugs use in aspirin and COX-2 inhibitor subgroups and the short or middle term treatment ( $\leq 5$ years) had significance GC risk reduction (Table 3). Further, as shown in Supplementary Figure S1, years of aspirin intake was positively associated with RR in a linear regression model, but the outcome without statistically significance $(\mathrm{F}=1.69, \mathrm{P}=0.210)$. We have to point out that only three studies were included in the old regression model [18], which is short for statistic power. However, all available data (twentyone studies) were enrolled in our novel model. Thus, our results more reliable than the old one. In addition, another interesting finding was that high-frequency ( $>30$ times per month) and low dose ( $<200 \mathrm{mg}$ per day) anti-inflammatory drug intake likely an optimal benefit regiment for GC prevention. Similarly, it is commonly reported in many colorectal cancer studies [68]. A potential explain for this phenomenon might be relative low dose NSAIDs exposure avoid of many side effects such as peptic ulcers $[69,70]$.

Second, our data also suggest that COX-2 inhibitors use is a more effective approach to reduce GC risk, which may have an important clinical usage for the treatment of GC and certain diseases. Above all, we clearly showed that COX-2 inhibitors intake with an encouraging significance $55 \%$ reduction in the risk of GC compare with $22 \%$ in total anti-inflammatory drug. Next, in other subgroup analysis, the pooled RR of three celecoxib studies involved also supported a result (RR: 0.49 , 95\% CI: 0.30-0.81), similar to COX-2 inhibitor intake does. Further, in the frequency and duration analysis, we found

that short-term ( $\leq 1$ years) daily COX-2 inhibitors intake is likely a better treatment than others for GC prevention. It has been reported that both mRNA expression and levels of COX-2 protein are elevated in GC tissue [71]. In last ten years, many animal and clinical studies have disclosed the chemopreventive effect of COX-2 inhibitors; and in particular, a few studies have strongly stated that COX-2 inhibitor prevents the development of GC [72]. In addition, another reason for COX-2 inhibitor intake in GC prevention is that COX-2 inhibitor has less side effects than the other NSAIDs. For instance, in COX-2 inhibitor user, the most serious adverse reaction is related to increase risk of serious cardiovascular harm [73]. Interestingly, it is reported that cardiovascular events elevated only when the dose over $400 \mathrm{mg}$ per day [74]. However, in our meta-analysis, the recommended of COX-2 inhibitor intake is low dose (<200 mg per day), which can avoid most of cardiovascular risk for the users. Additionally, selective COX-2 inhibitors can disturb renal physiology but the impacts are relatively weak and not clinically important. Accordingly, individuals are likely benefit a lot in COX-2 inhibitor intake for decrease GC risk and large-scale randomized clinical trial is further needed.

Third, the largest synthesis so far to our knowledge in the present study highlight that intake of NSAIDs intensely reduce the risk of GC. The protective rate can reach $22 \%$ after excluding the publication biases and using the adjusted dataset, but with a large between-study heterogeneity $(\mathrm{P}<0.0001$, $I^{2}=78.7 \%$ ). Indeed, after we kicked out six studies with relative low quality $[25,29,38,48,51,59,61]$, the heterogeneity dramatically decline to $39.0 \%(\mathrm{P}=0.007$, $\left.I^{2}=39.0 \%\right)$ and the reduction of GC risk still significant (RR, 0.74; 95\% CI, 0.71-0.77.). Hence, the main source 
of heterogeneity may in view of the fact that the relative low quality studies enrolled in the metaanalysis. Previously, several meta-analyses have found aspirin or NSAIDs use inversely associated with GC risk [16-18, 20], but we still have a problem that all those studies were short of statistic power and recently data. For example, the largest scale study were generally enrolled twenty-one qualified studies range from1968 to 2003 and the summary RR was also with a high heterogeneity $\left(I^{2}=59.8 \%\right)$. In our study, we searched a multitude of online dataset and eventually forty-seven studies were included in our analysis, among of which nineteen new studies were never covered in the previous meta-analyses [19, 22-29, 38, $39,44,49-51,53,56,58-60]$. Nevertheless, since the deficiency of randomized clinical trials, the strength of this study was impaired for drawbacks associated with an army of observational investigations.

\section{Conclusions and Implications}

In conclusion, unlike early studies, this metaanalysis is a more comprehensive and better designed study which conducted in both RCTs and observational studies and deeply discuss the most optimal regiment of anti-inflammatory drug exposure for $\mathrm{GC}$ risk reduction. It demonstrates clearly that short or middle-term ( $\leq 5$ years), high-frequency ( $>30$ times per month) and low dose ( $<200 \mathrm{mg}$ per day) antiinflammatory drug use is associated with a statistically significant reduction in the risk of GC. In addition, our data also strongly suggest that COX-2 inhibitors use is a more effective approach to reduce GC risk. However, because of potential bias and confounding factors, these results should be treated with caution. As a consequence, more and better-designed high relevant large clinical trials is an urgent need in the future.

\section{Supplementary Material}

Supplementary figures and tables.

http://www.jcancer.org/v07p2247s1.pdf

\section{Acknowledgments}

This study was supported by grants from Natural Science Foundation of Guangdong, China (No. 2015A030313010), Science and Technology Program of Guangzhou, China (No. 1563000305) and National Natural Science Foundation of China (No. 81272641and No. 81572409). The authors thank Dr. Yixin Zhou for statistical advising and review of the manuscript and Xuan Lee, and Min Ma for review of the manuscript.

\section{Authors' Contributions}

Conception and design: LPX, DZX, ZWZ, PFK. Development of methodology: PFK, RYW, XCL.
Acquisition of data: PFK, RYW, XCL, JJL, ZS, CJ.

Analysis and interpretation of data: PFK, RYW, XCL, SXC, MTY, CLY, QY, FXL.

Writing, review, and/or revision of the manuscript: PFK, RYW, XCL, RJP, WZH, CXY

Administrative, technical, or material support:

PFK, RYW, XCL, JJL, SXC.

Study supervision: LPX, DZX, ZWZ, RJP.

\section{Competing Interests}

The authors have declared that no competing interest exists.

\section{References}

1. Torre LA, Bray F, Siegel RL, Ferlay J, Lortet-Tieulent J, Jemal A. Global cancer statistics, 2012. CA: a cancer journal for clinicians. 2015; 65: 87-108.

2. Hartgrink HH, Jansen EP, van Grieken NC, van de Velde CJ. Gastric cancer. Lancet. 2009; 374: 477-90

3. Wang D, Dubois RN. Prostaglandins and cancer. Gut. 2006; 55: 115-22.

4. Giovannucci E, Rimm EB, Stampfer MJ, Colditz GA, Ascherio A, Willett WC. Aspirin use and the risk for colorectal cancer and adenoma in male health professionals. Annals of internal medicine. 1994; 121: 241-6.

5. Thun MJ, Henley SJ, Patrono C. Nonsteroidal anti-inflammatory drugs as anticancer agents: mechanistic, pharmacologic, and clinical issues. Journal of the National Cancer Institute. 2002; 94: 252-66.

6. Shaheen NJ, Straus WL, Sandler RS. Chemoprevention of gastrointestinal malignancies with nonsteroidal antiinflammatory drugs. Cancer. 2002; 94: 95063.

7. Leung KH, Mihich E. Prostaglandin modulation of development of cellmediated immunity in culture. Nature. 1980; 288: 597-600.

8. Fosslien E. Molecular pathology of cyclooxygenase-2 in neoplasia. Annals of clinical and laboratory science. 2000; 30: 3-21.

9. Krysan K, Reckamp KL, Dalwadi H, Sharma S, Rozengurt E, Dohadwala M, et al. Prostaglandin E2 activates mitogen-activated protein kinase/Erk pathway signaling and cell proliferation in non-small cell lung cancer cells in an epidermal growth factor receptor-independent manner. Cancer research. 2005; 65: 6275-81.

10. Gillies M, Skyring A. Gastric ulcer, duodenal ulcer and gastric carcinoma: a case-control study of certain social and environmental factors. The Medical journal of Australia. 1968; 2: 1132-6.

11. Akre K, Ekstrom AM, Signorello LB, Hansson LE, Nyren O. Aspirin and risk for gastric cancer: a population-based case-control study in Sweden. British journal of cancer. 2001; 84: 965-8.

12. Duan L, Wu AH, Sullivan-Halley J, Bernstein L. Nonsteroidal antiinflammatory drugs and risk of esophageal and gastric adenocarcinomas in Los Angeles County. Cancer epidemiology, biomarkers \& prevention: a publication of the American Association for Cancer Research, cosponsored by the American Society of Preventive Oncology. 2008; 17: 126-34.

13. Epplein M, Nomura AM, Wilkens LR, Henderson BE, Kolonel LN. Nonsteroidal antiinflammatory drugs and risk of gastric adenocarcinoma: the multiethnic cohort study. American journal of epidemiology. 2009; 170: 507-14.

14. Farrow DC, Vaughan TL, Hansten PD, Stanford JL, Risch HA, Gammon MD, et al. Use of aspirin and other nonsteroidal anti-inflammatory drugs and risk of esophageal and gastric cancer. Cancer epidemiology, biomarkers \& prevention: a publication of the American Association for Cancer Research, cosponsored by the American Society of Preventive Oncology. 1998; 7: 97-102.

15. Gammon MD, Terry MB, Arber N, Chow WH, Risch HA, Vaughan TL, et al. Nonsteroidal anti-inflammatory drug use associated with reduced incidence of adenocarcinomas of the esophagus and gastric cardia that overexpress cyclin D1: a population-based study. Cancer epidemiology, biomarkers \& prevention: a publication of the American Association for Cancer Research, cosponsored by the American Society of Preventive Oncology. 2004; 13: 34-9.

16. Wang WH, Huang JQ, Zheng GF, Lam SK, Karlberg J, Wong BC. Non-steroidal anti-inflammatory drug use and the risk of gastric cancer: a systematic review and meta-analysis. Journal of the National Cancer Institute. 2003; 95: 1784-91.

17. Tian W, Zhao Y, Liu S, Li X. Meta-analysis on the relationship between nonsteroidal anti-inflammatory drug use and gastric cancer. European journal of cancer prevention: the official journal of the European Cancer Prevention Organisation. 2010; 19: 288-98.

18. Ye X, Fu J, Yang Y, Gao Y, Liu L, Chen S. Frequency-risk and duration-risk relationships between aspirin use and gastric cancer: a systematic review and meta-analysis. PloS one. 2013; 8: e71522

19. Friis S, Sorensen HT, McLaughlin JK, Johnsen SP, Blot WJ, Olsen JH. A population-based cohort study of the risk of colorectal and other cancers among users of low-dose aspirin. British journal of cancer. 2003; 88: 684-8. 
20. Yang P, Zhou Y, Chen B, Wan HW, Jia GQ, Bai HL, et al. Aspirin use and the risk of gastric cancer: a meta-analysis. Digestive diseases and sciences. 2010; 55: 1533-9.

21. Cook NR, Lee IM, Gaziano JM, Gordon D, Ridker PM, Manson JE, et al. Lowdose aspirin in the primary prevention of cancer: the Women's Health Study: a randomized controlled trial. Jama. 2005; 294: 47-55.

22. Ajdarkosh H, Sohrabi M, Moradniani M, Rakhshani N, Sotodeh M, Hemmasi $\mathrm{G}$, et al. Prevalence of gastric precancerous lesions among chronic dyspeptic patients and related common risk factors. European journal of cancer prevention: the official journal of the European Cancer Prevention Organisation. 2015; 24: 400-6.

23. Gong EJ, Ahn JY, Jung HY, Lim H, Choi KS, Lee JH, et al. Risk factors and clinical outcomes of gastric cancer identified by screening endoscopy: a casecontrol study. Journal of gastroenterology and hepatology. 2014; 29: 301-9.

24. Jung S, Park CH, Kim EH, Shin SJ, Chung H, Lee H, et al. Preventing metachronous gastric lesions after endoscopic submucosal dissection through Helicobacter pylori eradication. Journal of gastroenterology and hepatology. 2015; 30: 75-81.

25. Sheu BS, Tsai YC, Wu CT, Chang WL, Cheng HC, Yang HB. Long-term celecoxib can prevent the progression of persistent gastric intestinal metaplasia After H. pylori eradication. Helicobacter. 2013; 18: 117-23.

26. Steevens J, Schouten LJ, Goldbohm RA, van den Brandt PA. Alcohol consumption, cigarette smoking and risk of subtypes of oesophageal and gastric cancer: a prospective cohort study. Gut. 2010; 59: 39-48.

27. Wong BC, Zhang L, Ma JL, Pan KF, Li JY, Shen L, et al. Effects of selective COX2 inhibitor and Helicobacter pylori eradication on precancerous gastric lesions. Gut. 2012; 61: 812-8.

28. Wu CY, Wu MS, Kuo KN, Wang CB, Chen YJ, Lin JT. Effective reduction of gastric cancer risk with regular use of nonsteroidal anti-inflammatory drugs in Helicobacter pylori-infected patients. Journal of clinical oncology: official journal of the American Society of Clinical Oncology. 2010; 28: 2952-7.

29. Wu Y, Fan Y, Jiang Y, Wang Y, Liu H, Wei M. Analysis of risk factors associated with precancerous lesion of gastric cancer in patients from eastern China: a comparative study. Journal of cancer research and therapeutics. 2013; 9: 205-9.

30. Stang A. Critical evaluation of the Newcastle-Ottawa scale for the assessment of the quality of nonrandomized studies in meta-analyses. European journal of epidemiology. 2010; 25: 603-5.

31. Galbraith RF. A note on graphical presentation of estimated odds ratios from several clinical trials. Statistics in medicine. 1988; 7: 889-94.

32. Kong P, Cai Q, Geng Q, Wang J, Lan Y, Zhan Y, et al. Vitamin intake reduce the risk of gastric cancer: meta-analysis and systematic review of randomized and observational studies. PloS one. 2014; 9: e116060.

33. Isomaki HA, Hakulinen T, Joutsenlahti U. Excess risk of lymphomas, leukemia and myeloma in patients with rheumatoid arthritis. Journal of chronic diseases. 1978; 31: 691-6.

34. Gridley G, McLaughlin JK, Ekbom A, Klareskog L, Adami HO, Hacker DG, et al. Incidence of cancer among patients with rheumatoid arthritis. Journal of the National Cancer Institute. 1993; 85: 307-11.

35. Thun MJ, Namboodiri MM, Calle EE, Flanders WD, Heath CW, Jr. Aspirin use and risk of fatal cancer. Cancer research. 1993; 53: 1322-7.

36. Schreinemachers DM, Everson RB. Aspirin use and lung, colon, and breast cancer incidence in a prospective study. Epidemiology. 1994; 5: 138-46.

37. Cibere J, Sibley J, Haga M. Rheumatoid arthritis and the risk of malignancy. Arthritis and rheumatism. 1997; 40: 1580-6.

38. Thrombosis prevention trial: randomised trial of low-intensity oral anticoagulation with warfarin and low-dose aspirin in the primary prevention of ischaemic heart disease in men at increased risk. The Medical Research Council's General Practice Research Framework. Lancet. 1998; 351: 233-41.

39. Awan A, Johnston DE, Jamal MM. Gastric outlet obstruction with benign endoscopic biopsy should be further explored for malignancy. Gastrointestinal endoscopy. 1998; 48: 497-500.

40. Zaridze D, Borisova E, Maximovitch D, Chkhikvadze V. Aspirin protects against gastric cancer: results of a case-control study from Moscow, Russia. International journal of cancer Journal international du cancer. 1999; 82: 473-6.

41. Suleiman UL, Harrison M, Britton A, McPherson K, Bates T. H2-receptor antagonists may increase the risk of cardio-oesophageal adenocarcinoma: a case-control study. European journal of cancer prevention: the official journal of the European Cancer Prevention Organisation. 2000; 9: 185-91.

42. Langman MJ, Cheng KK, Gilman EA, Lancashire RJ. Effect of antiinflammatory drugs on overall risk of common cancer: case-control study in general practice research database. Bmj. 2000; 320: 1642-6.

43. Coogan PF, Rosenberg L, Palmer JR, Strom BL, Zauber AG, Stolley PD, et al. Nonsteroidal anti-inflammatory drugs and risk of digestive cancers at sites other than the large bowel. Cancer epidemiology, biomarkers \& prevention: a publication of the American Association for Cancer Research, cosponsored by the American Society of Preventive Oncology. 2000; 9: 119-23.

44. Fischbach LA, Correa P, Ramirez H, Realpe JL, Collazos T, Ruiz B, et al. Antiinflammatory and tissue-protectant drug effects: results from a randomized placebo-controlled trial of gastritis patients at high risk for gastric cancer. Alimentary pharmacology \& therapeutics. 2001; 15: 831-41.

45. Sorensen HT, Friis S, Norgard B, Mellemkjaer L, Blot WJ, McLaughlin JK, et al. Risk of cancer in a large cohort of nonaspirin NSAID users: a population-based study. British journal of cancer. 2003; 88: 1687-92

46. Nomura AM, Hankin JH, Kolonel LN, Wilkens LR, Goodman MT, Stemmermann GN. Case-control study of diet and other risk factors for gastric cancer in Hawaii (United States). Cancer causes \& control: CCC. 2003; 14: 54758 .

47. Ratnasinghe LD, Graubard BI, Kahle L, Tangrea JA, Taylor PR, Hawk E. Aspirin use and mortality from cancer in a prospective cohort study. Anticancer research. 2004; 24: 3177-84.

48. Lindblad M, Lagergren J, Garcia Rodriguez LA. Nonsteroidal antiinflammatory drugs and risk of esophageal and gastric cancer. Cancer epidemiology, biomarkers \& prevention: a publication of the American Association for Cancer Research, cosponsored by the American Society of Preventive Oncology. 2005; 14: 444-50.

49. James MW, Chen CM, Goddard WP, Scott BB, Goddard AF. Risk factors for gastrointestinal malignancy in patients with iron-deficiency anaemia. European journal of gastroenterology \& hepatology. 2005; 17: 1197-203.

50. Yang HB, Cheng HC, Sheu BS, Hung KH, Liou MF, Wu JJ. Chronic celecoxib users more often show regression of gastric intestinal metaplasia after Helicobacter pylori eradication. Alimentary pharmacology \& therapeutics. 2007; 25: 455-61.

51. Leung WK, Ng EK, Chan FK, Chan WY, Chan KF, Auyeung AC, et al. Effects of long-term rofecoxib on gastric intestinal metaplasia: results of a randomized controlled trial. Clinical cancer research: an official journal of the American Association for Cancer Research. 2006; 12: 4766-72.

52. Fortuny J, Johnson CC, Bohlke K, Chow WH, Hart G, Kucera G, et al. Use of anti-inflammatory drugs and lower esophageal sphincter-relaxing drugs and risk of esophageal and gastric cancers. Clinical gastroenterology and hepatology: the official clinical practice journal of the American Gastroenterological Association. 2007; 5: 1154-9 e3.

53. Flossmann E, Rothwell PM, British Doctors Aspirin T, the UKTIAAT. Effect of aspirin on long-term risk of colorectal cancer: consistent evidence from randomised and observational studies. Lancet. 2007; 369: 1603-13.

54. Sadeghi S, Bain CJ, Pandeya N, Webb PM, Green AC, Whiteman DC, et al. Aspirin, nonsteroidal anti-inflammatory drugs, and the risks of cancers of the esophagus. Cancer epidemiology, biomarkers \& prevention: a publication of the American Association for Cancer Research, cosponsored by the American Society of Preventive Oncology. 2008; 17: 1169-78.

55. Figueroa JD, Terry MB, Gammon MD, Vaughan TL, Risch HA, Zhang FF, et al Cigarette smoking, body mass index, gastro-esophageal reflux disease, and non-steroidal anti-inflammatory drug use and risk of subtypes of esophageal and gastric cancers by P53 overexpression. Cancer causes \& control: CCC. 2009; 20: 361-8.

56. Hoyo C, Schildkraut JM, Murphy SK, Chow WH, Vaughan TL, Risch H, et al. IGF2R polymorphisms and risk of esophageal and gastric adenocarcinomas. International journal of cancer Journal international du cancer. 2009; 125: 2673 8

57. Abnet CC, Freedman ND, Kamangar F, Leitzmann MF, Hollenbeck AR, Schatzkin A. Non-steroidal anti-inflammatory drugs and risk of gastric and oesophageal adenocarcinomas: results from a cohort study and a metaanalysis. British journal of cancer. 2009; 100: 551-7.

58. Manas MD, Domper A, Albillos A, Hernandez A, Carpintero P, Lorente R, et al. Endoscopic follow-up of gastric ulcer in a population at intermediate risk for gastric cancer. Revista espanola de enfermedades digestivas: organo oficial de la Sociedad Espanola de Patologia Digestiva. 2009; 101: 317-24.

59. Yanaoka K, Oka M, Yoshimura N, Deguchi H, Mukoubayashi C, Enomoto S, et al. Preventive effects of etodolac, a selective cyclooxygenase-2 inhibitor, on cancer development in extensive metaplastic gastritis, a Helicobacter pylorinegative precancerous lesion. International journal of cancer Journal international du cancer. 2010; 126: 1467-73.

60. Gonzalez CA, Pardo ML, Liso JM, Alonso P, Bonet C, Garcia RM, et al. Gastric cancer occurrence in preneoplastic lesions: a long-term follow-up in a high-risk area in Spain. International journal of cancer Journal international du cancer. 2010; 127: 2654-60.

61. Bertuccio P, Bravi F, Bosetti C, Negri E, La Vecchia C. Aspirin and gastric cancer risk. European journal of cancer prevention: the official journal of the European Cancer Prevention Organisation. 2010; 19: 426-7.

62. Rothwell PM, Fowkes FG, Belch JF, Ogawa H, Warlow CP, Meade TW. Effect of daily aspirin on long-term risk of death due to cancer: analysis of individual patient data from randomised trials. Lancet. 2011; 377: 31-41.

63. Lee J, Lee SH, Hur KY, Woo SY, Kim SW, Kang WK. Statins and the risk of gastric cancer in diabetes patients. BMC cancer. 2012; 12: 596.

64. Dinarello CA. Anti-inflammatory Agents: Present and Future. Cell. 2010; 140: 935-50.

65. Cook NR, Lee IM, Zhang SM, Moorthy MV, Buring JE. Alternate-day, low-dose aspirin and cancer risk: long-term observational follow-up of a randomized trial. Annals of internal medicine. 2013; 159: 77-85.

66. Burn J, Gerdes AM, Macrae F, Mecklin JP, Moeslein G, Olschwang S, et al. Long-term effect of aspirin on cancer risk in carriers of hereditary colorectal cancer: an analysis from the CAPP2 randomised controlled trial. Lancet. 2011; 378: 2081-7.

67. Gu Q, Wang JD, Xia HH, Lin MC, He H, Zou B, et al. Activation of the caspase$8 /$ Bid and Bax pathways in aspirin-induced apoptosis in gastric cancer. Carcinogenesis. 2005; 26: 541-6.

68. Din FV, Theodoratou E, Farrington SM, Tenesa A, Barnetson RA, Cetnarskyj R, et al. Effect of aspirin and NSAIDs on risk and survival from colorectal cancer. Gut. 2010; 59: 1670-9.

69. Rothwell PM, Price JF, Fowkes FG, Zanchetti A, Roncaglioni MC, Tognoni G, et al. Short-term effects of daily aspirin on cancer incidence, mortality, and non- 
vascular death: analysis of the time course of risks and benefits in 51 randomised controlled trials. Lancet. 2012; 379: 1602-12.

70. Yeomans ND, Lanas AI, Talley NJ, Thomson AB, Daneshjoo R, Eriksson B, et al. Prevalence and incidence of gastroduodenal ulcers during treatment with vascular protective doses of aspirin. Alimentary pharmacology \& therapeutics. 2005; 22: 795-801.

71. Ristimaki A, Honkanen N, Jankala H, Sipponen P, Harkonen M. Expression of cyclooxygenase-2 in human gastric carcinoma. Cancer research. 1997; 57: 127680 .

72. Nam KT, Hahm KB, Oh SY, Yeo M, Han SU, Ahn B, et al. The selective cyclooxygenase-2 inhibitor nimesulide prevents Helicobacter pylori-associated gastric cancer development in a mouse model. Clinical cancer research : an official journal of the American Association for Cancer Research. 2004; 10: 810513.

73. FitzGerald GA, Patrono C. The coxibs, selective inhibitors of cyclooxygenase2. The New England journal of medicine. 2001; 345: 433-42.

74. Solomon SD, McMurray JJ, Pfeffer MA, Wittes J, Fowler R, Finn P, et al. Cardiovascular risk associated with celecoxib in a clinical trial for colorectal adenoma prevention. The New England journal of medicine. 2005; 352: 107180 . 